\title{
Linear focal elastosis
}

INSERM

\section{Source}

INSERM. (1999). Orphanet: an online rare disease and orphan drug data base. Linear focal elastosis. ORPHA:228236

Linear focal elastosis is a rare, acquired, dermis elastic tissue disorder characterized by asymptomatic, palpable, hypertrophic or atrophic, yellowish or red, indurated, horizontal, striae-like linear plaques distributed symmetrically across the mid and lower back. No systemic involvement has been described. Skin biopsy reveals a focal increase in abnormal elastic tissue with abundant, wavy, fragmented and aggregated, basophilic elastic fibers in the reticular dermis. 